\title{
'Scrutinised, judged and sabotaged': A qualitative video diary study of first-time breastfeeding mothers
}

Authors: Alison Taylor, Edwin van Teijlingen, Kath Ryan, Jo Alexander

Journal: Midwifery

\section{Please cite this paper as:}

Taylor, A., van Teijlingen, E., Ryan, K., Alexander, J. (2019) 'Scrutinised, judged and sabotaged': A qualitative video diary study of first-time breastfeeding mothers, Midwifery 75: 16-23.

\section{Abstract \\ Objective}

To explore how support impacted on mothers' breastfeeding experiences in the first few weeks following birth.

\section{Design}

A qualitative approach explored real-time experiences of breastfeeding captured by five first-time mothers in the South of England on camcorder as video diaries. A multi-dimensional approach involving thematic analysis ensured both the audio and visual elements of the data were analysed.

\section{Findings}

Mothers felt 'under surveillance' by the biomedical approach to support from the healthcare team. At best mothers felt reassured that they were 'on the right track'. When mothers felt their breastfeeding was constantly being examined, criticised and threatened they felt 'scrutinised, judged and sabotaged'. When they found it difficult to access healthcare support, or they avoided it altogether to circumvent further scrutiny, they felt 'abandoned and alone'.

\section{Key conclusions}

Collecting audio-visual data in real-time adds fresh insights into how support impacts mothers' experiences of breastfeeding. The biomedical approach to support for breastfeeding is not effective. Scrutinising, judging and/or sabotaging mothers' attempts to breastfeed can have long-lasting effects on maternal emotional wellbeing.

Implications for practice

Breastfeeding support might be improved by adopting a more social model of care. Future research needs to explore how relationship-based support can be provided by the health service.

Keywords: postnatal breastfeeding support, healthcare professionals, mothers' experiences, video diaries, biomedical approach 


\section{Introduction}

Exclusive breastfeeding is recommended for the first six months of life, continuing alongside appropriate complementary foods until at least two years (World Health Organization, 2003), based on its benefits for both mother and baby (Victora et al., 2016). The UK has the lowest rates of breastfeeding at one year globally (Victora et al., 2016). Data for England (2016-17) showed that whilst $74.5 \%$ of mothers initiated breastfeeding only $44.4 \%$ were partially breastfeeding at 6-8 weeks (Public Health England, 2017). Over $80 \%$ of mothers gave up breastfeeding and/or introduced formula before they wanted to (McAndrew et al., 2012). UNICEF UK Baby Friendly Initiative (BFI) standards (2012) state that maternity services need to ensure mothers initiate breastfeeding and health visiting services support mothers to maintain breastfeeding for as long as they wish. However, it is still a 'postcode lottery' whether or not services meet UNICEF BFI standards (2012). A Cochrane review concluded that the 'duration and exclusivity of breastfeeding' is increased when face-to-face support is offered by trained health professionals or peer supporters that is planned, predicted and 'tailored to the needs of the population' (McFadden et al., 2017, p. 29). NICE (2006, p. 63) states health professionals should prioritise care to ensure enough time is offered to support mothers who are breastfeeding their babies.

The culture on hospital wards may result in mothers facing many challenging encounters with health professionals because of their medicalised power and authority. Baker and colleagues (2005) found that breastfeeding mothers either felt a need to defend themselves or felt isolated and inadequate because staff attitudes and behaviour were controlling, intimidating, bullying and pressurising, or support was not provided at all. Dykes (2005), as a participant observer, witnessed time pressures on staff which affected breastfeeding support, including mechanised postnatal ward routines, disengaged communication, little individualised support and limited, rushed information. Studies identified mothers' uncomfortable feelings when professionals invaded their personal space by touching their breasts to provide hands-on breastfeeding (Marshall et al., 2007). Mothers felt supported when professionals developed a reciprocal relationship, taking time to listen using a non-judgmental, encouraging approach, observing feeding, providing practical individualised support, building esteem with positive affirmation and showing empathy, which encouraged them to continue (Dykes, 2005; Graffy et al., 2005; Marshall et al., 2007).

Conflicting advice and opinions cause confusion and mistrust of breastfeeding (Graffy et al., 2005; Marshall et al., 2007; McFadden and Toole, 2006). Such a biomedical approach or model (van Teijlingen, 2005) to support, meant that mothers rarely heard from the health-care team about practices that supported the natural flow of breastfeeding. Rather mothers felt undermined in their breastfeeding, when professionals 
suggested the use of a bottle teat or nipple shield to tease the baby onto the breast, and encouraged formula supplements for a 'perceived' hungry baby (Graffy et al., 2005), or to improve infant weight gain (Sachs et al., 2006). Recognising the power and authority imposed on them, some mothers used strategies to maintain control of their own decision making, including deciding when (not) to seek support, (Hoddinott and Pill, 1999; Shakespeare et al., 2004), lying to avoid conflict (Hoddinott and Pill, 2000) and accepting or rejecting advice (Marshall et al., 2007). Hoddinott and Pill (2000) noticed that mothers were often passive about seeking support, waiting for health professionals to offer it first. Given that many mothers do not have breastfeeding role-models (Thorley, 2019) and health professionals adhere to a biomedical approach, it is understandable that mothers feel uncertain and undermined.

Much of the qualitative research exploring women's experiences of breastfeeding has used retrospective interview or collected data contemporaneously by participant observation (Dykes, 2005; Marshall et al., 2007), interviews and written diaries (Hawkins and Heard, 2001). More recently research using audio diaries has focused on discourse, including verbal and linguistic detail around breastfeeding and expressing breastmilk but there was no visual data to enhance our understanding further (Johnson et al., 2012; Leeming et al., 2015). There is a paucity of evidence exploring women's experiences of breastfeeding in their everyday lives, on an ongoing basis using both visual and verbal data, without the researcher being present. Thus rather than a retrospective view, this study uses audio visual data to provide a prospective view, focusing on how health professionals' support impacted on mother's breastfeeding experiences.

\section{Methods}

Focusing on their own experiences of breastfeeding in the first few weeks after birth, first time mothers were asked to collect real-time data in their own socio-cultural environment with camcorders. Using an ethnographic approach, this audio-visual data collection method enabled the researchers to appreciate women's trials and tribulations by providing an "emic perspective" (Galvin and Holloway, 2017, p. 167). It also facilitated an "etic perspective" as the camcorder gave the women an active role in the research like a "participant observer", at the same time as providing the researcher with audio-visual data about the socio-cultural context (Bates, 2013, p. 30) of the mothers' breastfeeding environment. Other details of the design of this study are described elsewhere (Taylor et al. forthcoming ).

\section{Pilot study}

In a pilot study, one participant (Vicky) kept a video diary until she felt infant feeding was established. Although appearing uneasy initially, Vicky rapidly gained confidence recording almost daily for four months. The pilot highlighted that it could take this length of time for a woman to feel that her feeding 
method was established. The quantity, quality, breadth and richness of the data exceeded expectations and thus, along with new understandings gained about the research method, the pilot data were included in the main study.

\section{Recruitment}

Previous studies involving daily video diaries included three (Pocock et al., 2009) to 20 participants (Rich et al., 2000). This number appeared to generate an enormous amount of data as corroborated by our pilot study. Consequently, with more than 11 hours of data from the pilot study, the number of participants was reduced to five.

Midwives in the South of England approached English-speaking women expecting their first baby. To gain informed consent, interested women were visited at home by the first author and given the camcorder for about two weeks to practise. After the birth, if the mother was in good health and breastfeeding her first full-term baby, the camcorder was reissued for data collection within a day of her returning home. Out of seven women who consented, four mothers fitted these inclusion criteria. The five mothers in total, including the pilot participant, were 20-29 years old, two were married and three cohabiting and they all identified themselves as white British. According to the Office for National Statistics Standard Occupational Classification Hierarchy (2010), their socio-economic groups before birth ranged from group 2 to 10, with group 10 added for unemployed, students, voluntary work. One woman (Rosie) had a water birth at home, three had normal births in hospital (Sam, Sarah and Vicky) and Tracey had a forceps delivery (Taylor et al., forthcoming ). The two maternity and community services offering care to mothers during this study were both working towards UNICEF UK BFI accreditation.

\section{Data collection}

Each participant was given a camcorder to record what was important to her about breastfeeding in daily video diaries until she perceived that her infant method was established hence the data collection period was determined by the mother (Taylor et al., forthcoming). Written guidance was provided, being careful not to direct or restrict the daily dialogue (Willig, 2013), with a wide range of suggestions to trigger conversation, including experiences of and thoughts about breastfeeding, feelings before, during and after a breastfeed, most pleasurable aspects of feeding, dislikes or difficulties with breastfeeding as they occurred.

\section{Analysis}


Instead of the complex task of transcribing audio and visual data with potential inaccuracy (Markle et al., 2011), diaries were watched and logged in a sequential series of events.

By repeatedly viewing small sections of the video diaries, 'essence capturing' enabled open coding of the entire set of data (Saldaña, 2016). This iterative strategy enabled a multi-factorial analysis allowing the authors to identify the socio-cultural perspectives of breastfeeding. This involved coding the visual such as mother's facial expressions, direction of gaze, body language, emotions and what she chose to frame in the video recording (Kristensen, 2018) alongside the linguistic detail using a straightforward cut, drag, drop method in NVivo (Bazely and Jackson, 2013). A total of 170 codes were identified including both (a) explicit, "data-derived" codes; and (b) interpretive "researcher-derived codes" (Braun and Clarke 2013, p. 208). These 170 codes were combined into 27 categories. By developing and merging concepts, the categories were grouped together to form provisional subthemes which were then organised into broader themes.

\section{Reflexivity}

The first author used a reflexive approach which included being aware that although she wasn't present during mothers' video recordings, she was still implicit in the study (Brown et al. 2010). Bates (2015, p. 10) suggested that the video method is best considered as: "a sensory method, not simply because it blends what we see with what we hear, but because it evokes a sense of feeling..." ensuring the researcher's voice was added as a 'voice over theirs' (Pocock et al. 2009, p. 411). The first author as a midwife and mother could empathise with the sights, sound, smells and textures that were presented and evoked. A mother fumbling while changing a soiled eco-friendly nappy or milk spraying as a baby suddenly loses attachment to the breast during a letdown of milk, evoked senses of smell and touch that she too had experienced. Sometimes the angry outbursts, though not directed at the first author personally, felt invasive. Thus, her experience as a mother and midwife enhanced the analysis process, because it meant that a multitude of senses were stimulated, tapping into a tacit knowledge, assisting in a corporeal, embodied interpretation of everyday life with a breastfeeding baby. As mothers 'poured out their hearts', we sometimes felt ashamed and let down by fellow health professionals and at other times the first author wanted to but refrained from, rushing in to help and offering advice as a midwife.

\section{Trustworthiness}

To maintain trustworthiness, all co-authors (midwife, sociologist and a pharmacist) scrutinised the methods, analysis and interpretations of the data providing an inter-professional perspective and ensured the themes were not over-represented (Shenton, 2004). Any disagreements were resolved by discussion.

\section{Ethical Issues}


Informed written consent was requested from participants when extensive discussion and a leaflet were given about the project including confidentiality and anonymity issues and risks and possible benefits of participation (Anderson and Muñoz Proto, 2016). Informed written consent was an ongoing process, being obtained each time data was collected with the option to abstain/withdraw at any stage (Tenney and MacCubbin, 2008).

Because there was an intention to disseminate the findings to a wide audience, participants were informed of the risk that confidentiality and anonymity could not be maintained once data was released for dissemination which might mean they could be recognised and judged by someone familiar to them (Anderson and Muñoz Proto, 2016). This was explained thoroughly to participants using reality TV as an example. Additionally, to ensure that only video footage that they were comfortable about sharing was used, mothers were shown how to edit their own recordings before releasing them for analysis (Whiting et al., 2018). Thus participants were empowered to create videos that represented their views, voices and experiences in a meaningful way (Anderson and Muñoz Proto, 2016) and the balance of power was at least partly shifted from researcher to participant (Brown et al., 2010).

Recognising the potential that psychological stress might be caused by recording and/or editing the video diaries, the midwife-researcher, looked for signs of this when collecting data from the participant's home and within the video footage (Ryan et al., 2011) so that the mother could be advised to stop video recording and offered a referral to a specialist. Whilst there was a host of emotions recorded, these were rather a result of talking about their experiences and this appeared to be cathartic (Taylor et al. forthcoming ).

The first author explained to participants about safeguarding issues, such as images or discussion on the video diaries about physical, sexual or psychological abuse, that might need to be reported to the authorities (Nursing Midwifery Council, 2015) and to hand over any images as evidence to the police.

Ethical approval was gained from the local NHS Ethics committee and the University Ethics Committee.

\section{Findings}

Eight weeks initially anticipated in the research proposal. Sam stopped filming at 8 weeks but others recorded on a regular basis between nine and twelve weeks, with two filming but taking longer breaks after 12 weeks until 18 and 20 weeks respectively (Taylor et al. forthcoming ). Two hundred and ninety four video recordings were submitted in total amounted to over 43 hours of video recording. The length of 
recordings was very varied, depending on why mothers chose to record and what they had to share, from a few seconds to over 1 hour and 10 minutes. The average length recordingsalso varied with Sam recording on average for nearly five minutes, Sarah and Vicky eight minutes, Tracey 12.5 minutes and Rosie 18 minutes.

This paper focuses on one theme which explores mothers' perceptions of being 'under surveillance' by the healthcare team. Mothers expressed their experience of the health service, feeling that they were under surveillance as their mothering skills, breastfeeding and development of their baby were under continual review by healthcare team members including midwives, health visitors, support workers and peer supporters. Mothers became keen critics, discussing individual members of the 'surveillance team', evaluating their practice in a measured way. This theme was derived from three subthemes, (1) on the right track?; (2) scrutinised, judged and sabotaged; and (3) abandoned and alone (Chart 1). 'On the right track?' comprised of mothers's experiences of being encouraged by the healthcare team with regular check-ups and nurturing support. The second subtheme was at the other end of the spectrum as mothers felt breastfeeding was 'scrutinised judged and sabotaged' which led to frequent and lengthy emotional offloading on camcorder by scrutinising the scrutineer' and condemning the surveillance programme and the team members involved. 'Abandoned and alone' described mothers' feelings when they did not access or did not receive the support they needed from the healthcare team. Pseudonyms are used followed by the age of the baby in weeks.

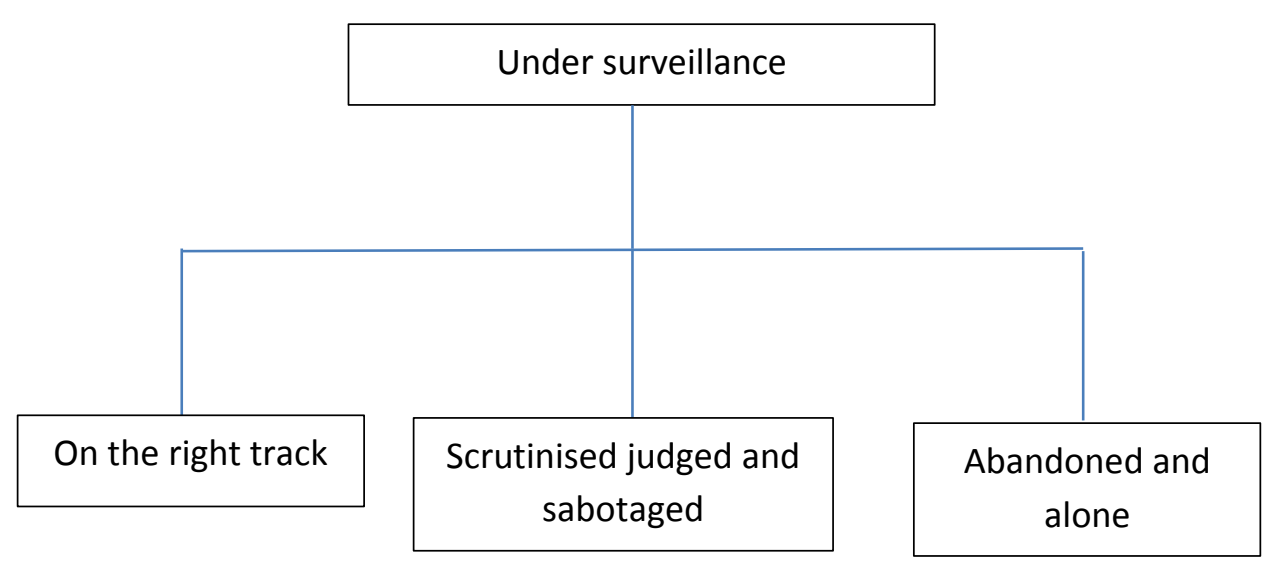

Table 1: Theme: Under surveillance

\section{On the right track?}


Mothers who experienced opportunities to build relationships and trust with healthcare workers, felt encouraged to ask whether they were 'on the right track?' without fear of judgement. This felt nurturing and affirming particularly when their baby was progressing well. This reciprocal relationship was enhanced when they felt on an equal footing with staff.

We had... a midwife support worker ... and it somehow felt it's not quite so bad to say something to her because she isn't an official midwife (Rosie1).

Healthcare workers who actively listened to concerns were considered especially nurturing as even the most well-informed mothers initially doubted their ability to breastfeed successfully. Any reassurance that breastfeeding was 'working' was affirming.

Quite nice that she was there to watch in real-time... she wasn't in a rush. ... said it's right... it's a good feeling to know it's right... never having done it before, it's not obvious what is right and what is not, and you can be in fear or doubt as to whether it's working (Rosie1)

With a determination to work through difficulties, mothers required frequent validation that breastfeeding was going well through routine check-ups. For all mothers, weight gain was key, such validation revolved around a biomedical reassurance that their baby was growing, emphasising the nutritional importance rather than relational benefits of breastfeeding.

She's now 8lbs ... that has given me a real boost knowing that although I'm sore, although I might be a bit miserable about it, the very fact that Sophie is putting on weight means that she's taking milk and it's doing its job. (Sarah1)

Healthcare workers who were sensitive to the mother's needs chose the right time to provide information to encourage breastfeeding. Being forewarned was being forearmed so that mothers were not fazed by some of the breastfeeding challenges and were less likely to be alarmed, discouraged or give up.

The health visitor confirmed what I have been thinking, it's still such early days and completely normal that it's [feeding pattern] all a bit random and all over the place, and she said, 'don't expect it to settle down into any kind of routine for ... the first six or eight weeks', which is even longer than I had thought. (Rosie3)

\section{Scrutinised, judged and sabotaged}


All mothers expressed an overwhelming feeling that healthcare workers were not always checking they were 'on the right track' in a positive nurturing way. Instead they felt their parenting skills, including breastfeeding, were being scrutinised which made them wary that resulting advice could sabotage breastfeeding. This made them constantly on guard in case there was an unexpected visit from a healthcare worker.

...so I better make sure the house is smart, I better make sure I'm looking presentable...like I don't want to be caught out somehow...they could come at any moment and I want to keep them happy and...potentially they have some sort of power over me. (Rosie2)

Mothers' feelings of being judged and rendered powerless were even stronger when talking about initiating breastfeeding in hospital, as support was often rushed, overpowering, controlling or 'hands on'. The powerlessness felt by three mothers receiving 'hands on support', where midwives held their breast and pushed the baby on, or felt scrutinised by being constantly 'watched and criticised' whilst breastfeeding, was particularly evident.

The student midwife was actually trying to teach me how to do it with kind of, a hands-off approach, and just talking me through it, maybe try this, maybe try that...and an old school midwife came in and said, 'this is how you do it' and just plonked Sophie onto my boob... (Sarah1) I really wish someone had taken a little more time and not just plonked her on the boob because then we might not have all this soreness and miserableness. (Sarah2)

Tracey, distressed by incessant breastfeeding, did not feel listened to by hospital midwives who appeared more interested in breastfeeding than her wellbeing. The instructive approach was demoralising and she felt degraded being forced to expose her breasts to staff. Hence, she expressed her distress on video about feeling singled out and judged as a bad mother by the staff who kept saying that her baby was hungry. She had limited understanding that it was normal for babies to feed very frequently in the first few days. Her expectations were at odds with her reality, resulting in feelings of intimidation and hopelessness.

I was instructed to lie down and show this midwife everything which I wasn't very happy about, because I feel very conscious of my chest area...Got told that I was to continue feeding my baby... because of all this I just felt l'd failed my baby (Tracey1)

Fearing further criticism for not coping once they were home, mothers worked out strategies to minimise negative judgements, including concealing real issues whilst keeping up appearances; agreeing with professionals' advice to create a good impression but ignoring it; and conforming to advice against their 
better judgement. Mothers analysing their situation on camera, preferred a route of least resistance to gain inner peace and privacy.

...so she said, well done, carry on as you're doing. Brilliant! Exhausting! Last week she told me not to feed for more than 20 minutes on each side, didn't tell her I wasn't doing this. (Vicky4)

The health visitor has been going on and on about baby massage to me and I thought, you know, Zac will hate it because he hates being naked, and he just screams but I thought, you know, to shut them up I'm just going to go. (Sam6)

This study demonstrated the lasting and damaging effects of staff not showing respect. When Tracey's baby was not gaining adequate weight, she felt scrutinised and humiliated. In repeated video entries, she expressed deep emotional turmoil when describing the authoritarian approach adopted by healthcare workers, ranging from confusion, anxiety and low self-worth to anger. The extent of emotional turmoil recorded in the video diaries would not have been captured by a single interview. The antipathy shown by healthcare workers towards her breastfeeding was disempowering, demoralising and Tracey felt under direct sabotage, causing a tortuous dilemma between wanting to give up breastfeeding because it wasn't valued and wanting to carry on for the good of her baby.

She told me... if I didn't feed him, he'd look scrawny, and this week, it was 'look at the centile, oh that's not good, you need to bring it back up, are you feeding your baby?' ...Then with this other woman...she weighs [her] baby... and she says, 'ah perfect, on the centile, you are such a good boy, do you breast or bottle feed him?' The lady goes 'bottle' and she says, 'you are such a good mum'. (Tracey5)

This woman has really knocked my confidence by saying that my baby's scrawny and this is week 10 now... (Tracey11)

The mixed emotions displayed daily on camcorder that were related to feeling 'scrutinised' were part of the rollercoaster of emotions expressed. At times mothers felt anxious and defeated but at others they appeared defiant and fought back. When Tracy felt defeated she recognised how her confidence in breastfeeding had been crushed and sought moral support from her partner. At other times, she vented her anger during diary recordings as if talking to the very person who had upset her. This appeared to bring a cathartic release which seemingly made her more determined to continue breastfeeding.

The emotional damage that you have caused!... And the worry that I'm not being a good enough mum to my son is NOT ok... You need to change your attitudes. You're not doing your job properly... and you're NOT going to get to me anymore. I've made a decision... I don't care what you have to 
say, my baby is putting on weight, he will do it in his own time... My baby comes first and what my baby tells me to do, I will do... I don't care about it anymore, I'm going to relax, you are NOT going to make my milk dry out and I'm NOT buying formula, that is the end of it. (Tracey6)

This study also demonstrated the effect of conflicting advice when most participants verbalised their confusion, attempting to work out which route to follow over several diary entries. Conflicting opinions combined with scrutiny, caused mothers and their partners to become confused, anxious and vulnerable, affecting both breastfeeding and a close relationship with their baby.

And I noticed this morning that my right nipple was a bit bloody... when she started sucking I was cheeeeeee...so mentioned that to her [health care assistant] and she watched me feeding and gave some tips... and it's not always consistent one person to the next, one midwife to the next (Rosie1)

[Scott said] ...in hospital there should be one way that's taught and one way only because it's quite unsettling and bewildering when you think, 'oh. I'm doing what that midwife said to do' and then ten minutes later someone else comes in and says, 'no you do it like this, you do it like that' and you just think, well give me a break. (Tracey1)

When staff gave conflicting advice they lost credibility, resulting in mothers becoming confused or ignoring them. For example, when members of the 'surveillance programme' were unclear about which growth chart to use for a breastfeeding baby, one mother expressed further anguish and feelings of being sabotaged.

I just got a phone call... to say that this chart... is not correct and that the one in my red book is. Well a couple of hours ago, she said the one in my red book isn't the correct one and that there is one for breastfeeding babies... I feel really let down, I thought these people were supposed to help you (Tracey6)

The fear of being scrutinised spilled over into fear and intimidation when attending peer support groups. The potential for support from other mothers was marred by the idea that someone could be judgemental and advice could be unhelpful or disparaging. Indeed, these fears were realised when some mothers were forced to expose their breasts making them feel intimidated, anxious and humiliated.

It was my first session... I was so nervous. It was horrible. I was worried that she would have a go at me because I was doing it wrong. I was worried that she would have an opinion on me. I only went once. I found it quite daunting. (Sam8) 
Mothers' experiences were not empowering or encouraging and thus to prevent themselves feeling judged further, they avoided attending again.

\section{Abandoned and alone}

Mothers felt abandoned when adequate support was not received.

In hospital, I wasn't actually shown how to breastfeed, or offered any assistance... I got a shock when I came home the same day... it was quite painful at first... I struggled in the night, I found he wasn't latching on, he was restless... (Sam1)

Sarah resented the lack of appropriate support which resulted in delay in the diagnosis of her baby's tongue-tie, leading to her feeling abandoned with self-doubt and despair. In retrospect, she blamed this poor assessment for all her breastfeeding problems and the extreme pain and misery that ensued.

I will always feel disappointed and always feel let down by the system really... that quick look under the tongue and a quick snip will actually do an awful lot for mothers... the pain was incredible, it curled my toes and [I] wished my baby wouldn't wake up so I didn't have to feed her again (Sarah9)

Feeling 'scrutinised' caused mothers to feel anxious for fear of being judged for not following advice or reaching the necessary milestones for the 'surveillance programme'. To circumvent judgements, they purposefully avoided contact by not attending groups or clinics and not arranging appointments. Avoiding the 'officially available' support resulted in mothers continuing to feel alone and abandoned.

I am still a little bit embarrassed that she's having some bottles... I've got this fear of what if I'm feeding and feeding and feeding her while I'm there and she's not satisfied and I have to get the bottle in a breastfeeding group, and I don't want to go and that be a problem. (Sarah7)

Not accessing support left mothers in a quandary as to what to do next. This exacerbated the feeling of abandonment resulting in expressions of loneliness and helplessness amidst seemingly insurmountable problems. They needed someone who would listen with time, respect, support and positive affirmation to help them work out their issues and to move on.

I'm lonely as well, I wish there was somebody I could talk to really, [pause] and trust, that isn't patronising, that talks nicely to you... so I'm just really agitated... if this doesn't resolve itself then I think I'm going to have to go to bottle feeding (Tracey3) 
Feeling abandoned also occurred when services were not available causing further anxiety when help was needed most. Turning to family was sometimes their only option despite having reservations about causing relatives anxiety and being at potential risk of being judged by them.

I did try ringing the health visitor I couldn't get hold of anybody, no-one's there, I don't have an emergency number for anyone, so really it was fend for yourself, it being a Friday. (Sam2)

I think it's important for people to understand the pressure that it puts onto family as well... if I tell my mum... she's going to start worrying... but l'm just going to have to do it because l've got no-one else to speak to (Tracey3)

\section{Discussion}

Mothers experienced the medicalisation of infant feeding by surveillance that at best reassured them that they were on the 'right track', but at worst sabotaged breastfeeding by being disrespectful, judgemental, and authoritarian. Using video diaries, mothers became keen critics, evaluating the practice of the 'surveillance team'. Although mothers talked about valuing the opportunities for reciprocal relationships built on trust, there were relatively few and brief examples of this approach. In the study by Flaherman et al., (2012) mothers appeared fixated by their babies' weight, rather than seeing and believing that their baby was thriving through the relational side of breastfeeding.

In this study a breastfeeding-centred rather than person-centred approach characterised the medicalised scrutiny that mothers experienced in hospital. The medical model of care within midwifery has become an established approach that "prevents, manages and controls risk or risky situations" to avoid untoward incidences and litigation (MacKenzie Bryers and van Teijlingen, 2010, p. 488). Application of this medical model prompted the healthcare team to control breastfeeding using excessive monitoring and early 'hands on' support to minimise risks of morbidity but ignored evidence that supports infant self-attachment promoting wellbeing in both mother and baby (Bergman, 2013) including self-efficacy in the mother. This medicalised approach where women quietly complied with the 'hands on' practice, in direct contrast to their later expression of surprise regarding lack of consent and dislike of this corporal invasion, has been highlighted elsewhere (Burns et al., 2013; Hunter et al., 2015). In addition, feelings of humiliation, intimidation and insecurity were triggered when mothers felt forced to expose their breasts for someone to watch feeding, as reported by teenage mothers (Hunter et al., 2015) and mothers with severe breastfeeding difficulties (Palmér et al., 2012).

The risk averse medicalised approach to breastfeeding support found in this study to be prescriptive, contradictory, authoritarian, and disrespectful was consistent with international research analysed in two 
meta-syntheses (Beake et al., 2012; Burns et al., 2010) and additional evidence published subsequently (Hoddinott et al., 2012; Palmér et al., 2012; Spencer et al., 2015). In this study, the same medical model was applied in the community setting involving mothers attending clinics, babies being weighed and measurements plotted on graphs. Parallels can be drawn with the Francis Report (2010), where communication and attitudes of nursing staff were described by witnesses as 'sharp', 'surly,' 'unsympathetic', 'dismissive and rude'. The Department of Health (DOH (2009, p. 6) defined dignity as:

... the kind of care, in any setting, which supports and promotes, and does not undermine, a person's self-respect regardless of any difference.

This study, adds a further dimension by suggesting the biomedical approach has not been working and offering valuable insights into the damaging and lasting effects of healthcare workers' attitudes when they showed a lack of respect for mothers. Hinsliff-Smith and colleagues (2014), also highlighted the ongoing emotional rollercoaster endured in the first six weeks following birth. While identifying discontent with professionals' support, however, they did not attribute the emotional disturbance to them specifically, but to mothers feeling ill prepared for frequent feeding, exhaustion and the guilt experienced when giving up. This study added to these findings with audio-visual evidence of how the mothers ascribed their emotions to their feelings of persistent scrutiny by the healthcare team and how the feelings persisted and fluctuated in strength over hours and days. However it is interesting that Palmér et al. (2015) have suggested that when mothers are able to blame others for their breastfeeding difficulties, they are more likely to continue breastfeeding.

Conflicting information given to mothers about breastfeeding is widely reported (Fox et al., 2015; Leeming et al., 2015; Whelan and Kearney, 2014). This study demonstrated the long-lasting effect of conflicting advice on most participants as they verbalised their confusion and anxiety over several diary entries. The UNICEF UK Baby Friendly Initiative Standards (2012, p. 2) state that all staff must be educated "according to their role and the service provided" not just to prevent conflicting messages but also medicalisation of breastfeeding. Whelan and Kearney (2014) interviewing health professionals and breastfeeding women agreed that there was a necessity for all health professionals to receive training about breastfeeding in order to prevent conflicting messages and medicalisation of breastfeeding. Providing consistent support does not mean scrutinising mothers' parenting and breastfeeding skills. To avoid feeling judged, mothers developed strategies to give the impression that they were coping and did not share their concerns but, in their video diaries, expressed a need to be listened to with time, respect, support and positive affirmation to help them work through their issues. Spencer at al. $(2015$, p. 1082) exploring mothers' experiences of breastfeeding, also found that mothers created "illusions of compliance". According to Hunter (2006), not 
sharing way could have produced imbalanced exchanges between mother and health professional, reducing reciprocity, so that supporting the mother effectively became difficult. A reciprocal relationship with women can provide individualised care, but Hunter (2006) recognised this as a complex issue.

Schmied and colleagues (2011, pp. 51-53) discussed the importance of providing "an authentic presence" and using a "facilitative style" to support breastfeeding mothers effectively. These approaches require the health professional to embrace a two-way relationship, taking time to explore what is important to mothers and to observe a feed, helping them feel relaxed, providing positive and sensitive affirmation and encouragement and sharing realistic information and practical support. The evidence from Thomson and Dykes' (2011) study, has also been used to underpin the updated UNICEF UK BFI standards (Entwistle, 2013, p. 79) which require supporters of breastfeeding to adopt "relation-based support". However, Schmied and colleagues (2008) revealed that even when midwives understood the evidence that underpins the importance of building reciprocal relationships with mothers, they were unable to find the time to use this approach on the postnatal ward. With historic underfunding for provision of postnatal care in England (NHS England, 2016) it is perhaps not surprising that mothers in this study did not experience "relation-based support". Thus, whilst UNICEF BFI standards do increase long-term breastfeeding rates (Spaeth et al., 2017), this research suggests that unless the medicalised, risk averse, time-pressured approach to support is changed, mothers will continue to feel scrutinised with restricted opportunities for "relation-based support".

\section{Strengths and limitations}

This study is unique in using audio-visual diaries to explore support offered to breastfeeding mothers. Since the findings were based on five white British mothers they may not be generalisable. Nevertheless, findings were consistent with those presented in other qualitative studies but with enhanced understandings of real-time support issues for mothers.

Participants were aware that the primary researcher was a midwife, and this could have influenced them in how they wanted to represent themselves as mothers when recording their video dairies. However, as they became accustomed to filming, they expressed thoughts, feelings and emotions about the support they had received in unanticipated ways. Thus, a strength of this study was how mothers impulsively recorded their experiences, providing new insights into the long-lasting and negative impact of the current biomedical support received.

\section{Conclusion}


Medicalised surveillance at best reassured mothers that they were on the right track but at worst sabotaged breastfeeding because mothers felt victimised by the perceived authoritarian, didactic, disrespectful approaches used by some healthcare workers. When mothers felt judged or scrutinised, their communication with staff was affected. Therefore, mothers did not always engage in reciprocal relationships by sharing concerns, thoughts and feelings. Healthcare workers need to be aware that a reciprocal relationship will not develop while mothers feel they are being judged or scrutinised. The audiovisual data provided fresh insights into the lasting and damaging effects on mothers' emotions when they felt they had not been treated with dignity and respect. The current medicalised approach to support does not provide the consistency, time, respect, support and positive affirmation that mothers need, leaving them feeling confused, anxious and isolated. In addition, if peer support groups are not accessed in pregnancy, they can be daunting for mothers with breastfeeding problems.

Maternity services in general, and breastfeeding support in particular, might improve if staff work towards a more social model of care. Future research needs to explore how relationship-based support can be provided by maternity services to improve breastfeeding experiences and outcomes.

Anderson, S.M., Muñoz Proto, C., 2016. Ethical Requirements and Responsibilities in Video Methodologies : Considering Confidentiality and Representation in Social Justice Research. Soc. Personal. Psychol. Compass 10, 377-389.

Baker, S.R., Henshaw, C.H., Tree, J., 2005. "I Felt as though I"d been in Jail': Women's Experiences of Maternity Care during Labour, Delivery and the Immediate Postpartum. Fem. Psychol. 15, 315-342. https://doi.org/10.1177/0959-353505054718

Bazely, P., Jackson, K., 2013. Qualitative Data Analysis with Nvivo, 2nd ed. Sage Publications Ltd, London.

Beake, S., Pellowe, C., Dykes, F., Schmied, V., Bick, D., 2012. A systematic review of structured compared with non-structured breastfeeding programmes to support the initiation and duration of exclusive and any breastfeeding in acute and primary health care settings. Matern. Child Nutr. 8, 141-161. https://doi.org/10.1111/j.1740-8709.2011.00381.x

Bergman, N., 2013. Breastfeeding and Perinatal Neuroscience, in: Watson Genna, C. (Ed.), Supporting Suckling Skills in Breastfeeding Infants. Jones and Bartlett, New York, pp. 43-57.

Brown, C., Costley, C., Friend, L., Varey, R., 2010. Capturing their dream: Video diaries and minority consumers. Consum. Mark. Cult. 13, 419-436. https://doi.org/10.1080/10253866.2010.502420

Burns, E., Fenwick, J., Sheehan, A., Schmied, V., 2013. Mining for liquid gold: midwifery language and practices associated with early breastfeeding support. Matern. Child Nutr. 9, 57-73. https://doi.org/10.1111/j.1740-8709.2011.00397.x

Burns, E., Schmied, V., Sheehan, A., Fenwick, J., 2010. A meta-ethnographic synthesis of women's experience of breastfeeding. Matern. Child Nutr. 6, 201-219. https://doi.org/10.1111/j.17408709.2009.00209.x 
Department of Health, 2009. Final report on the review of the Department of Health Dignity in Care Campaign. [online] London: DOH. Available from:

http://www.dignityincare.org.uk/_library/Opinion_Leader_Final_Report_to_DH.doc.pdf [Accessed 19 June 2015].

Dykes, F., 2005. A critical ethnographic study of encounters between midwives and breast-feeding women in postnatal wards in England. Midwifery 21, 241-252. https://doi.org/10.1016/j.midw.2004.12.006

Entwistle, F., 2013. The evidence and rationale for the UNICEF UK Baby Friendly Initiative standards. [online] London: UNICEF UK. Available from:

http://www.unicef.org.uk/Documents/Baby_Friendly/Research/baby_friendly_evidence_rationale.pd $\mathrm{f}$ [Accessed 2 June 2015].

Flaherman, V.J., Hicks, K.G., Cabana, M.D., Lee, K.A., 2012. Maternal Experience of Interactions With Providers Among Mothers With Milk Supply Concern. Clin. Pediatr. (Phila). 51, 778-784. https://doi.org/10.1177/0009922812448954

Fox, R., McMullen, S., Newburn, M., 2015. UK women's experiences of breastfeeding and additional breastfeeding support: a qualitative study of Baby Café services. BMC Pregnancy Childbirth 15, 147. https://doi.org/10.1186/s12884-015-0581-5

Francis, R., 2010. Foundation Trust Inquiry Independent Inquiry into care provided by Mid Staffordshire NHS Foundation Trust January 2005 - March 2009. Volume II. [online] London: The Stationary Office. Available from: https://www.gov.uk/government/uploads/system/uploads/attachment_data/file/279107/0375_ii.pdf [Accessed 20 June 2015].

Galvin, K., Holloway, I., 2017. Qualitative research in nursing and healthcare, 4th ed. ed. Wiley Blackwell, Chichester.

Graffy, J., Taylor, J., Hons, B., 2005. What Information, Advice, and Support Do Women Want With Breastfeeding ? Birth 32, 179-186.

Hawkins, A., Heard, S., 2001. An exploration of the factors which may affect the duration of breastfeeding by first time mothers on low incomes -- a multiple case study. MIDIRS Midwifery Dig. 11, 521-6.

Hinsliff-Smith, K., Spencer, R., Walsh, D., 2014. Realities, difficulties, and outcomes for mothers choosing to breastfeed: primigravid mothers experiences in the early postpartum period (6-8 weeks). Midwifery 30, e14-e19. https://doi.org/10.1016/j.midw.2013.10.001

Hoddinott, P., Craig, L., Britten, J., M Mclnnes, R., 2012. A serial qualitative interview study of infant feeding experiences: idealism meets realism. BMJ Open 2, 1-17. https://doi.org/10.1136/bmjopen2011-000504

Hoddinott, P., Pill, R., 2000. A qualitative study of women's views about how health professionals communicate about infant feeding. Heal. Expect. 3, 224-233. https://doi.org/10.1046/j.13696513.2000.00108.x

Hoddinott, P., Pill, R., 1999. Nobody actually tells you: a study of infant feeding. Br. J. Midwifery 7, 558565.

Hunter, B., 2006. The importance of reciprocity in relationships between community-based midwives and mothers. Midwifery 22, 308-322. https://doi.org/10.1016/j.midw.2005.11.002

Hunter, L., Magill-Cuerden, J., McCourt, C., 2015. Disempowered, passive and isolated: how teenage 
mothers' postnatal inpatient experiences in the UK impact on the initiation and continuation of breastfeeding. Matern. Child Nutr. 11, 47-58. https://doi.org/10.1111/mcn.12150

Johnson, S., Leeming, D., Lyttle, S., Williamson, I., 2012. Empowerment or Regulation? Women's Perspectives on Expressing Milk, in: Hall Smith, P., Hausman, B., Labbok, M. (Eds.), Beyond Health, Beyond Choice: Breastfeeding Constraints and Realities. Rutgers University Press, New Brunswick, pp. 180-189.

Kristensen, L.K., 2018. "Peeling an onion": layering as a methodology to promote embodied perspectives in video analysis. Video J. Educ. Pedagog. 3, 1-21. https://doi.org/10.1186/s40990-018-0015-1

Leeming, D., Williamson, I., Johnson, S., Lyttle, S., 2015. Making use of expertise: A qualitative analysis of the experience of breastfeeding support for first-time mothers. Matern. Child Nutr. 11, 687-702. https://doi.org/10.1111/mcn.12033

MacKenzie Bryers, H., van Teijlingen, E., 2010. Risk, theory, social and medical models: A critical analysis of the concept of risk in maternity care. Midwifery 26, 488-496.

https://doi.org/10.1016/j.midw.2010.07.003

Markle, D., West, R., Rich, P., 2011. Beyond Transcription: Technology, Change, and Refinement of Method. Forum Qual. Soc. Res. 12, Art 21.

Marshall, J.L., Godfrey, M., Renfrew, M.J., 2007. Being a "good mother": managing breastfeeding and merging identities. Soc. Sci. Med. 65, 2147-2159. https://doi.org/10.1016/j.socscimed.2007.06.015

McAndrew, F., Thompson, J., Fellows, L., Large, A., Speed, M., Renfrew, M.J., 2012. Infant Feeding Survey 2010. [online] Dundee: The Information Centre for Health and Social Care. Available from: http://data.gov.uk/dataset/infant-feeding-survey-2010 [Accessed 2 June 2015].

McFadden, A., Gavine, A., Renfrew, M.J., Wade, A., Buchanan, P., Taylor, J.L., Veitch, E., Rennie, A.M., Crowther, S.A., Neiman, S., MacGillivray, S., 2017. Support for healthy breastfeeding mothers with healthy term babies (Review). Cochrane Database Syst. Rev. Issue 2.

McFadden, A., Toole, G., 2006. Exploring women's views of breastfeeding: A focus group study within an area with high levels of socio-economic deprivation. Matern. Child Nutr. 2, 156-168. https://doi.org/10.1111/j.1740-8709.2006.00054.x

National Institute for Health and Care Excellence, 2006. Postnatal care up to 8 weeks after birth [WWW Document]. NICE.

NHS England, 2016. National Maternity Review. Better Births: Improving outcomes of maternity services in England: A Five Year Forward View for maternity care [WWW Document].

Nursing Midwifery Council, 2015. The Code: Professional standards of practice and behaviour for nurses and midwives. [online] London: Nursing and Midwifery Council. Available from: http://www.nmc.org.uk/globalassets/sitedocuments/nmc-publications/revised-new-nmc-code.pdf [Accessed 5 June 2015].

Office for National Statistics, 2010. ONS Standard Occupational Classification (SOC) Hierarchy [WWW Document]. URL http://www.neighbourhood.statistics.gov.uk/HTMLDocs/dev3/ONS_SOC_hierarchy_view.html (accessed 10.3.15).

Palmér, L., Carlsson, G., Brunt, D., Nyström, M., 2015. Existential security is a necessary condition for continued breastfeeding despite severe initial difficulties: a lifeworld hermeneutical study. Int. 
Breastfeed. J. 10, 1-12. https://doi.org/10.1186/s13006-015-0042-9

Palmér, L., Carlsson, G., Mollberg, M., Nyström, M., 2012. Severe breastfeeding difficulties: Existential lostness as a mother - Women's lived experiences of initiating breastfeeding under severe difficulties. Int. J. Qual. Stud. Health Well-being 7, 1-11. https://doi.org/10.3402/qhw.v7i0.10846

Pocock, N., Zahra, A., Mcintosh, A., 2009. Proposing Video Diaries as an Innovative Methodology in Tourist Experience Research. Tour. Hosp. Plan. Dev. 6, 109-119.

https://doi.org/10.1080/14790530902981480

Public Health England, 2017. Public health Profiles: Breastfeeding [WWW Document].

Rich, M., Lamola, S., Gordon, J., Chalfen, R., 2000. Video intervention/prevention assessment: a patientcentered methodology for understanding the adolescent illness experience. J. Adolesc. Heal. 27, 15565.

Ryan, K., Brown, S., Wilkins, C., Taylor, A., Arnold, R., Angell, C., Van Teijlingen, E., 2011. Which hat am I wearing today? Practising midwives doing research. Evid. Based Midwifery 9.

Sachs, M., Dykes, F., Carter, B., 2006. Feeding by numbers: an ethnographic study of how breastfeeding women understand their babies' weight charts. Int. Breastfeed. J. 1, 1- 11.

https://doi.org/10.1186/1746-4358-1-29

Saldaña, J., 2016. The Coding Manual for Qualitative Researchers. Sage Publications Ltd, London.

Schmied, V., Beake, S., Sheehan, A., McCourt, C., Dykes, F., 2011. Women's Perceptions and Experiences of Breastfeeding Support : A Metasynthesis. Birth 38, 49-60.

Schmied, V., Cooke, M., Gutwein, R., Steinlein, E., Homer, C., 2008. Time to listen: Strategies to improve hospital-based postnatal care. Women and Birth 21, 99-105.

https://doi.org/10.1016/j.wombi.2008.04.002

Shakespeare, J., Blake, F., Garcia, J., 2004. Breast-feeding difficulties experienced by women taking part in a qualitative interview study of postnatal depression. Midwifery 20, 251-260.

https://doi.org/10.1016/j.midw.2003.12.011

Shenton, A.K., 2004. Strategies for ensuring trustworthiness in qualitative research projects. Educ. Inf. 22, 63-75.

Spaeth, A., Zemp, E., Merten, S., Dratva, J., 2017. Baby-Friendly Hospital designation has a sustained impact on continued breastfeeding. Matern. Child Nutr. 14, 1-12. https://doi.org/10.1111/mcn.12497

Spencer, R.L., Greatrex-White, S., Fraser, D.M., 2015. "I thought it would keep them all quiet". Women's experiences of breastfeeding as illusions of compliance: an interpretive phenomenological study. J. Adv. Nurs. 71, 1076-1086. https://doi.org/10.1111/jan.12592

Taylor, A.M., van Teijlingen, E., Alexander, J., Ryan, K. 2018. The therapeutic role of video diaries: A qualitative study involving breastfeeding mothers, Women Birth (accepted). https://www.sciencedirect.com/science/article/pii/S1871519218300064

Tenney, L., MacCubbin, P., 2008. When No One Was Watching: Human Protections and Videotaping (Take 1), in: Downing, M., Tenney, L. (Eds.), Video Vision: Changing the Culture of Social Science Research. Cambridge Scholars Publishing, Newcastle upon Tyne, pp. 14-79.

Thomson, G., Dykes, F., 2011. Women's Sense of Coherence related to their infant feeding experiences. 
Matern. Child Nutr. 7, 160-174. https://doi.org/10.1111/j.1740-8709.2010.00251.x

Thorley, V., 2019. Is breastfeeding " normal "? Using the right language for breastfeeding. Midwifery 69, 39-44. https://doi.org/10.1016/j.midw.2018.10.015

UNICEF UK Baby Friendly Initiative, 2012. Guide to the Baby Friendly Initiative standards. [online] London: UNICEF UK BFI. Available from:

http://www.unicef.org.uk/Documents/Baby_Friendly/Guidance/Baby_Friendly_guidance_2012.pdf [Accessed 10 June 2015].

van Teijlingen, E. 2005. A critical analysis of the medical model as used in the study of pregnancy and childbirth, Sociological Res Online, 10 (2) Available from

http://www.socresonline.org.uk/10/2/teijlingen.html

Victora, C.G., Bahl, R., Barros, A.J.D., França, G.V.A., Horton, S., Krasevec, J., Murch, S., Sankar, M.J., Walker, N., Rollins, N.C., 2016. Breastfeeding in the 21st century: epidemiology, mechanisms, and lifelong effect. Lancet 387, 475-490.

Whelan, B., Kearney, J.M., 2014. Breast-feeding support in Ireland : a qualitative study of health-care professionals' and women 's views. Public Health Nutr. 18, 2274-2282.

https://doi.org/10.1017/S1368980014002626

Whiting, R., Symon, G., Roby, H., Chamakiotis, P., 2018. Who's Behind the Lens ? A Reflexive Analysis of Roles in Participatory Video Research. Organ. Res. Methods 21, 316-340. https://doi.org/10.1177/1094428116669818

World Health Organization, 2003. Global Strategy for Infant and Young Child. [online] Geneva: WHO. Available from: http://amro.who.int/english/ad/fch/ca/GSIYCF_infantfeeding_eng.pdf [Accessed 1 June 2015]. 